\title{
PLANEJAMENTO FINANCEIRO: ANÁLISE DO PERFIL DOS INVESTIDORES
}

Lucas de Souza Miranda, Claudio José Donato, Eduardo de Lima Silva, Hualacy Guilherme Odilon do Nascimento, Irene Caires da Silva, Leticia Moreira da Silva, Liége Xavier Martins, Maísa Ferreira Vieira, Tais Muller, Tatiana Veiga Uzeloto, Vinicius da Silva Soares.

Universidade do Oeste Paulista - UNOESTE, Presidente Prudente, SP. E-mail: claudio.donato@hotmail.com

\section{RESUMO}

Hoje, em virtude da instabilidade financeira do país, as pessoas precisam estar preparadas para situações adversas, com isso é preciso ter em mente que o planejamento financeiro é de suma importância para a estabilidade financeira, que precisam encontrar maneiras para obter crescimento econômico e crescer em um mercado globalizado e muito competitivo. Sendo assim, busca-se neste artigo realizar uma análise do perfil do investidor, mostrando os fatores que influenciam na escolha de seus investimentos. Este trabalho adotou a linha de pesquisa bibliográfica, com consulta a diversos autores, periódicos, sites específicos, e uma pesquisa com investidores. Para a coleta dos dados foi aplicado um questionário a um grupo de 100 investidores, pessoas físicas, e administradores de empresas, obtendo um retorno de 84 questionários que serviram como amostra de pesquisa. Os resultados mostraram os investidores em sua maioria possuem um perfil conservador e tendem a optar por investimentos que possuam conhecimento, tendo grande parte dos seus investimentos em aplicações de renda fixa de baixo risco.

Palavra-Chave: Aplicações. Investimentos. Investidores. Fatores. Perfil.

\section{FINANCIAL PLANNING: INVESTOR PROFILE ANALYSIS}

\begin{abstract}
Today, because of the country's financial instability, people need to be prepared for adverse situations, with this it is necessary to keep in mind that financial planning is of paramount importance for financial stability, they need to find ways to achieve economic growth and grow in a globalized and very competitive market. Thus, this article seeks to perform an analysis of the profile of the investor, showing the factors that influence the choice of their investments. This work has adopted the line of bibliographic research, with consultation to several authors, periodicals, specific sites, and a research with investors. For the data collection, a questionnaire was applied to a group of 100 investors, individuals, and business managers, obtaining a return of 84 questionnaires that served as a research sample. The results showed investors mostly have a conservative profile and tend to opt for investments that have knowledge, having a large part of their investments in low risk fixed income investments.
\end{abstract}

Keyword: Applications. Investments. Investors. Factors. Profile. 


\section{INTRODUÇÃO}

Em virtude da atual crise financeira que assola o país, em sua maioria, a população brasileira tem tido problemas financeiros, especialmente com dívidas, dificuldade para aquisição de bens e desemprego. Diante deste cenário, o descontrole financeiro, o acesso fácil a financiamentos, bem como a falta de planejamento são as maiores causas ao grande endividamento da população. Deste modo, é importante que os indivíduos adquiram hábitos de planejar e gerir os gastos, mas infelizmente, não existe educação para isso.

Conforme ressalta Macedo Jr. (2007), o planejamento financeiro deve funcionar como um guia para a vida cotidiana. Mostrar a situação atual do indivíduo, quais são as metas futuras, quais caminhos percorrer para ser bem-sucedido. Deste modo, por meio do planejamento, o indivíduo tem controle sobre seus gastos, além de começar a poupar também. Ser competente na gestão do próprio orçamento e estilo de vida deveria fazer parte das prioridades de todos e se torna fundamental para uma qualidade de vida sadia.

Hoje, os vários tipos de investimentos disponíveis no mercado para as pessoas físicas possibilitam ao investidor escolher entre aplicações de renda fixa ou variável, que atendam a suas necessidades de rendimento de acordo com suas convicções, conhecimentos e disponibilidades financeiras.

Juntamente com os tipos de investimentos disponíveis, surgem as dúvidas de qual a melhor opção para a aplicação dos recursos, sendo que os investidores necessariamente não têm as mesmas dúvidas e objetivos na hora de investir, podendo ter variações com relação às características de cada indivíduo.

Feitas estas considerações, o problema de pesquisa foi definido como sendo: Qual o perfil dos investidores e quais os fatores que influenciam na escolha de seus investimentos?

Neste contexto, dada à importância que o tema relacionado a investimentos e a investidores tem no atual momento da economia brasileira, esta pesquisa tem como objetivo identificar o perfil dos investidores e os fatores que os influenciam na escolha de seus investimentos.

A aplicação de recursos e o comportamento dos investidores são temas de grande relevância para pesquisas no meio acadêmico, desta forma, este estudo tem o objetivo de contribuir com as demais pesquisas existentes, reforçando alguns pontos e abrindo novas questões que poderão ser estudadas posteriormente.

\section{METODOLOGIA}

Quanto aos objetivos realizou-se uma pesquisa do tipo descritiva, sendo que através da coleta de dados serão apuradas as informações sobre os investidores, com a finalidade de analisar e caracterizar o perfil dos mesmos.

Com relação aos procedimentos foram utilizados os levantamentos de dados e pesquisas bibliográficas. O levantamento de dados foi feito em virtude da necessidade da obtenção de dados quantitativos. Já a pesquisa bibliográfica se torna obrigatória quando existe a necessidade do estudo de um problema ao qual se procura uma resposta.

O universo de pesquisa foram 100 investidores, pessoas físicas, e administradores de empresas, que residem na cidade Presidente Prudente-SP.

A amostra utilizada na pesquisa foi de 84 questionários que retornaram ao pesquisador. Esta amostra é considerada não probabilística do tipo de amostragem por conveniência. 
Para a coleta dos dados foi utilizado um questionário, composto de 17 questões de natureza fechada e de múltipla escolha, que foram enviados ao respondente e entregue posteriormente ao pesquisador.

Após o retorno dos questionários foi feita a análise e descrição dos resultados.

\section{RESULTADOS}

A amostra foi formada por 84 respondentes, dentre um universo de 100 investidores que receberam o questionário.

A questão 1 solicitou a idade do respondente, que foi dividida em cinco faixas, sendo que a faixa etária preponderante foi de 41 a 50 anos, com $40 \%$ do total da amostra, representado por 33 respostas.

Na questão 2 foi perguntado aos respondentes o seu enquadramento com relação ao sexo masculino ou feminino, sendo que o resultado obtido foi de $75 \%$ da amostra pertencentes ao sexo masculino.

A questão 3 objetivou enquadrar o respondente em seu respectivo estado civil, que teve como preponderante o grupo de casados ou com relação estável, representando $77 \%$ da amostra.

$\mathrm{Na}$ questão 4 foi solicitado aos respondentes o seu grau de escolaridade, representado em seis categorias, sendo que o resultado preponderante foi o de curso superior incompleto com $38 \%$ das respostas.

Através da questão 5 , buscou-se saber a renda familiar bruta do respondente, predominando com 54\%, os respondentes que possuem renda de $\mathrm{R} \$ 2.000,00$ a $\mathrm{R} \$ 4.000,00$.

Por fim, na questão 6 o objetivo foi saber qual o número de dependentes da renda familiar dos respondentes, sendo que o resultado predominante foi de 4 dependentes com $31 \%$ das respostas.

Atendendo aos objetivos específicos da pesquisa, a questão 7 procurou identificar qual o perfil dos investidores, utilizando para este fim a classificação encontrada no referencial, enquadrando os respondentes em conservador, moderado e agressivo.

Na questão foram utilizadas três frases, cada uma com características de um dos três perfis de investidor, sendo que o respondente deveria escolher qual a frase que identificava o que ele considera mais importante nos seus investimentos.

O resultado demonstrou que $61 \%$ os respondentes identificaram-se com o perfil conservador. Com $26 \%$ das respostas aparece o perfil moderado e com $13 \%$ o perfil agressivo.

A questão 8 objetivou saber quais os fatores que influenciam na opção dos investimentos por parte dos investidores.

A questão relacionou os seis principais fatores encontrados na revisão teórica, deixando espaço para que o investidor colocasse outro que por ventura não estivesse relacionado, sendo que o respondente deveria optar por aquele com maior influência.

O fator preponderante entre os investidores desta pesquisa foi "o conhecimento sobre o investimento escolhido" com $28 \%$, demonstrando a importância perante os investidores.

Outros três fatores mostraram-se relevantes ao ficarem com $17 \%$ das respostas, são eles: o rendimento oferecido pela aplicação, o objetivo do investimento e o tipo de risco apresentado no investimento.

Quando analisados os fatores que determinam a opção pelos investimentos relacionando estas respostas com o perfil dos investidores, constata-se que o conhecimento 
sobre o investimento escolhido tem maior incidência entre o perfil conservador e o moderado, com $27 \%$ e $36 \%$ respectivamente. Já no perfil agressivo destaca-se com $45 \%$ o rendimento oferecido pela aplicação.

Quando foi perguntado aos investidores de quem recebeu ou recebe orientações para decidir onde aplicar seus recursos, sendo que esta resposta foi relacionada com o perfil dos investidores. Para o perfil conservador o destaque com $45 \%$ das respostas foi para as orientações de seus familiares. Já os moderados recebem preferencialmente orientações de gerentes ou funcionários de instituições financeiras, com $64 \%$ das respostas. No perfil agressivo o destaque foi para a orientação de consultores com $71 \%$ das respostas.

Os resultados desta comparação apontam que os investidores moderados e agressivos buscam preferencialmente ajuda profissional para fazer seus investimentos, tendo em vista que uma das características destes perfis é a busca por rendimentos acima da renda fixa.

Foi solicitado ao investidor que escolhesse um objetivo dentre os relacionados na questão, demonstrando qual no seu entendimento seria mais importante na sua vida pessoal, sendo aberto para ele colocar outro, caso assim o entendesse. Para os conservadores o objetivo com maior representatividade foi o de conservar o patrimônio, mantendo uma reserva financeira para os imprevistos, com $53 \%$ das respostas, confirmando uma das características deste grupo de investidor.

Conforme Cavalcante Filho e Misumi (2002), o investidor conservador procura preservar o seu capital.

Para os investidores enquadrados nos perfis moderado e agressivo, o principal objetivo assinalado foi o de aumentar o patrimônio financeiro a longo prazo, com $50 \%$ e $55 \%$ das respostas respectivamente. Este resultado confirma uma característica destes dois grupos que é o investimento a longo prazo. Para Brum (2006), os investidores moderados e agressivos procuram investimentos de longo prazo buscando maior rentabilidade que a oferecida no mercado.

\section{DISCUSSÃO}

Através da pesquisa buscou-se identificar qual o perfil de um grupo de investidores e a relação entre o perfil e suas opções de investimento.

A amostra que foi base para esta pesquisa teve predominância de investidores entre 41 e 50 anos, do sexo masculino, com estado civil de casado/relação estável, com grau de escolaridade superior incompleto, renda familiar bruta entre $\mathrm{R} \$ 2.000,00$ e $\mathrm{R} \$ 4.000,00$ e com 4 dependentes da renda familiar.

Com relação ao perfil dos investidores verificou-se que a grande maioria dos respondentes foi enquadrada como conservador, com $61 \%$ das respostas, seguido dos moderados com $26 \%$ e dos investidores agressivos com $13 \%$. Desta forma, nota-se o quanto é importante para os profissionais ligados à área de investimentos conhecerem o perfil dos investidores, pois a carteira de investimentos indicada para os conservadores não é a mesma para os moderados ou agressivos. Os conservadores em geral aplicam em investimentos que apresentam baixo risco como poupança e imóveis. Já os investidores moderados, que buscam um retorno superior à renda fixa, mesclam investimentos de baixo risco com investimentos em renda variável. No caso de investidores com perfil agressivo, a maior parte de seus recursos geralmente estão alocados em investimentos de renda variável como ações. 
Ao analisar os fatores que influenciam na opção dos investimentos, constatou-se que "o conhecimento sobre o investimento escolhido" teve $28 \%$ das respostas, sendo o fator com maior influência no geral. Quando analisado em separado por perfis, o conhecimento ficou o grupo de conservadores com $27 \%$ e os moderados com $36 \%$, ou seja, demonstrando que estes dois perfis tendem a aplicar preferencialmente em investimentos que possuam conhecimento.

Este fato deve servir de alerta aos profissionais ligados a área de investimentos, pois devem ter a preocupação de orientar os investidores para que eles entendam claramente no que estão investindo. Para o grupo de investidores agressivos verificou-se que $45 \%$ são influenciados pelo rendimento oferecido pela aplicação, ou seja, para este grupo devem ser oferecidos investimentos que possam gerar rendimentos acima da média do mercado.

Ao verificar de que forma os investidores se compartam frente aos fatores que influenciam nas opções de investimentos, ressalta-se que mais de $60 \%$ de em todos os perfis recebem ou receberam auxílio no momento de investir, reforçando a importância dos profissionais ligados a área de investimentos estarem preparados para atender estes investidores, principalmente com relação a investimentos financeiros em $C D B$, fundos de renda fixa e variável, ações, clubes de investimento e previdência privada.

\section{CONCLUSÃO}

O Brasil vive um período de instabilidade financeira. Neste novo cenário da economia, cresce a importância do estudo sobre a melhor forma de aplicação de recursos, bem como de investimentos que contemplem as necessidades de cada investidor.

O mercado de investimentos possui vários produtos para a aplicação de recursos, porém eles não possuem as mesmas características de segurança, liquidez e rentabilidade.

Avaliando o objetivo proposto na pesquisa, pode-se constatar que ele foi totalmente alcançado, ressaltando que este trabalho deixa ao meio acadêmico vários pontos para pesquisas futuras, não se limitando aos resultados nele encontrados, sendo sugerido como forma de ampliar os estudos sobre o tema em questão uma pesquisa com empresários de outra região ou grupos de investidores não ligados ao meio empresarial.

\section{REFERÊNCIAS}

BRUM, Carlos A. H. Aprenda a Investir em Ações e a Operar na Bolsa Via Internet. 3. ed. Rio de Janeiro: Ciência Moderna, 2006.

CAVALCANTE FILHO, Francisco da Silva; MISUMI, Jorge Yoshio. Mercado de Capitais. Rio de Janeiro: Campus, 2002.

MACEDO JR., Jurandir Sell. A árvore do dinheiro: guia para cultivar sua independência financeira. Rio de Janeiro: Elsevier, 2007.

OLIVEIRA, Eliane; SILVA, Sandra M; VIEIRA, Wesley. S. Finanças comportamentais: Um estudo sobre o perfil comportamental do investidor e do propenso investidor. In: CONGRESSO ASSOCIAÇÃO NACIONAL DE PROGRAMAS DE PÓS-GRADUAÇÃO EM CIÊNCIAS CONTÁBEIS, 2, 2008, Salvador. Anais... Salvador: ANPCONT, 2008.

ROGERS, Pablo; FAVATO, Verônica; SECURATO. José R. Efeito educação financeira no processo de tomada de decisões em investimentos: um estudo a luz das finanças 
comportamentais. In: CONGRESSO ASSOCIAÇÃO NACIONAL DE PROGRAMAS DE PÓSGRADUAÇÃO EM CIÊNCIAS CONTÁBEIS, 2, 2008, Salvador. Anais... Salvador: ANPCONT, 2008. 